\title{
Counting Sulfhydryls and Disulfide Bonds in Peptides and Proteins Using Mercurial Ions as an MS-Tag
}

\author{
Yifei Guo, Liqin Chen, Limin Yang, and Qiuquan Wang \\ Department of Chemistry and the MOE Key Laboratory of Modern Analytical Sciences, College of Chemistry \\ and Chemical Engineering; and State Key Laboratory of Marine Environmental Science, Xiamen University, \\ Xiamen, China
}

Organic mercurial compounds are the most specific and sensitive reagents for reaction with the sulfhydryl groups (-SHs) in peptides and proteins because of the strong mercury-sulfur affinity. Using the monofunctional organic mercury ion $\mathrm{RHg}^{+}$as a mass spectrometry (MS)-tag has the advantages of reacting with one sulfhydryl group, offering definite mass shift, and especially stable and characteristic nonradioactive isotopic distribution. Mass spectrometric analysis of derivatized sulfhydryls in peptides/proteins is thus an alternative for precisely counting the number of sulfhydryl groups and disulfide bonds $(-\mathrm{S}-\mathrm{S}-)$. Here the tags used include monomethylmercury chloride, monoethylmercury chloride, and 4-(hydroxymercuri) benzoic acid. The feasibility of this strategy is demonstrated using HPLC/ESI-MS to count - SHs and $-\mathrm{S}-\mathrm{S}$ - in model peptides/proteins, i.e., glutathione, phytochelatins, lysozyme and $\beta$-lactoglobulin, which contain increasing - SHs and various - S - S linkages. (J Am Soc Mass Spectrom 2008, 19, 1108-1113) (c) 2008 American Society for Mass Spectrometry

$\mathrm{C}$ ysteine-free sulfhydryls (-SHs) of proteins are exceptionally useful in terms of both their structural and redox regulatory aspects. Some critical cysteine residues can either activate or deactivate protein functions in various physiologically important reactions and, increasingly, are being recognized as important modulators of protein function [1]. Disulfide bond $(-\mathrm{S}-\mathrm{S}-$ ) formation between $-\mathrm{SHs}$, a posttranslational modification, is vital for the correct folding and tertiary structure stability of many secreted and membrane proteins [2]. Therefore, identification of $-\mathrm{SH}$ and $-\mathrm{S}-\mathrm{S}$ - can give valuable information concerning the relationship between the structure and function of a protein. On the other hand, frequency analysis of amino acids in the proteomes of fully sequenced genomes shows that cysteine is one of the most rarely used amino acids in proteins across all superkingdoms [3]. Because of their ubiquity but lower abundance, - SHs provide a greater opportunity for saturating the reactive sites, resulting in more reproducible quantitative labeling and less impact on the proteins. Numerous spectrometric methods for determining the - $\mathrm{SH}$ s derivatized by alkylation agents have been reported [4,5]. Although there are increasing numbers of commercially available thiol-reactive dyes, such as iodoacetamide or maleimide, the application of these dyes to proteomic studies

Address reprint requests to Dr. Qiuquan Wang, Xiamen University, College of Chemistry and Chemical Engineering, Department of Chemistry and the MOE Key Laboratory of Modern Analytical Sciences, and State Key Laboratory of Marine Environmental Science, Xiamen 361005, China. E-mail: qqwang@xmu.edu.cn still has some limitations. Organic dyes often suffer from photobleaching; their molecules $(\sim 1 \mathrm{~nm}$ in diameter) are usually large in size, sometimes limiting their access to - SHs existing inside the configuration of a protein because of steric restrictions; and dye molecular rigidity might be destroyed for the sake of labeling, leading to fluorescence signal suppression. The functional groups with a selective reaction toward thiols include, but are not limited to, the iodoacetamide or maleimide moiety. Many monovalent and divalent metal ions can directly react with - SHs [6, 7] and, among them, mercurial compounds (especially organic mercurial compounds) are the most specific and sensitive reagents for reaction with - $\mathrm{SHs}$ because of the strong mercury-sulfur affinity [8,9]. Although relevant reports are scarce [10-13], one realizes the potential application of organic mercurial compounds and tries to expand them to several analytical platforms. Using the monofunctional organic mercury ion $\mathrm{RHg}^{+}$as a mass spectrometry (MS)-tag has the advantages of reacting with one - $\mathrm{SH}$, definite mass shift, and especially stable and characteristic nonradioactive isotopic distribution when monocharged derivatized peptides and proteins are monitored. Thus, mass spectrometric measurements of the - SHs derivatized by $\mathrm{RHg}^{+}$in peptides and/or proteins constitute an alternative strategy for counting - SHs and $-S-S-$ after suitable reduction.

This report describes the feasibility of using high performance liquid chromatography (HPLC) coupled with electrospray ionization mass spectrometry (ESIMS) to count the number of $-\mathrm{SHs}$ and $-\mathrm{S}-\mathrm{S}-$ in 
peptides and proteins using $\mathrm{RHg}^{+}$as an MS-tag. One can easily measure the exact numbers of $-\mathrm{SH}$ and - S-S - in peptides/proteins because the binding stoichiometry between $\mathrm{RHg}^{+}$and - $\mathrm{SH}$ can simply reach 1:1. Free - $\mathrm{SH}$ in peptides and/or proteins are treated directly with $\mathrm{RHg}^{+}$to label them, whereas $-\mathrm{S}-\mathrm{S}-$ in proteins are subjected to reduction by tris-(2-carboxyethyl)-phosphine (TCEP) and the resulting nascent - SHs are labeled immediately with $\mathrm{RHg}^{+}$ (Scheme 1). The labeled proteins can be isolated by HPLC and characterized by ESI-MS. The feasibility of this strategy is demonstrated by counting - SHs and - S-S - in model peptides/proteins, i.e., glutathione (GSH), phytochelatins (PCs), lysozyme, and $\beta$ lactoglobulin, which contain increasing - $\mathrm{SHs}$ and various $-\mathrm{S}-\mathrm{S}-$ linkages.

\section{Experimental}

Methylmercury chloride $\left(\mathrm{CH}_{3} \mathrm{HgCl} ;>95 \%\right)$ and ethylmercury chloride $\left(\mathrm{CH}_{3} \mathrm{CH}_{2} \mathrm{HgCl} ;>98 \%\right)$ were obtained from Alfa Aesar (Ward Hill, MA, USA), and 4-(hydroxymercuri) benzoic acid ( $\left.\mathrm{HOOC}-\mathrm{C}_{6} \mathrm{H}_{4}-\mathrm{HgOH}\right)$ from Fluka (Buchs, Switzerland). TCEP, $\beta$-lactoglobulin, and lysozyme were purchased from Sigma-Aldrich (St. Louis, MO, USA). GSH and tris(hydroxymethyl) aminomethane (Tris) were purchased from Sino-American Technology (Shanghai, China). Ultrapure water (UPW; $18 \mathrm{M} \Omega$ ) was prepared with a Milli-Q system (Millipore Filter Co., Bedford, MA, USA) and used throughout this study.

A solution of GSH ( $1 \mu \mathrm{M}$ in $50 \mu \mathrm{L}$ UPW) was added to small vials containing $10 \mu \mathrm{L} \mathrm{HOOC}-\mathrm{C}_{6} \mathrm{H}_{4}-\mathrm{HgOH}$ (10 $\mu \mathrm{M}$ in $1 \mathrm{mM} \mathrm{NaOH}$ solution) and $10 \mu \mathrm{L} \mathrm{CH} \mathrm{CH}_{3} \mathrm{HCl}$ (10 $\mu \mathrm{M}$ in methanol). The vials were sealed and vibrated in the dark for $20 \mathrm{~min}$ to ensure a complete reaction. $\mathrm{PC}_{3}$ was prepared as described previously [14]. $\mathrm{PC}_{3}(50 \mu \mathrm{L}, 15 \mu \mathrm{M})$ in Tris-buffer (20 mM, pH 7)

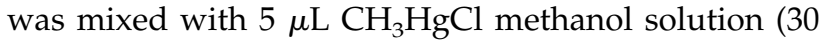
$\mathrm{mM}$ ) and $5 \mu \mathrm{L} \mathrm{HOOC}-\mathrm{C}_{6} \mathrm{H}_{4}-\mathrm{HgOH}(30 \mathrm{mM}$ in $1 \mathrm{mM}$ $\mathrm{NaOH}$ solution) and then the mixture was incubated in the dark at room temperature for $20 \mathrm{~min}$. Before derivatization, the disulfide bonds in lysozyme $(50 \mu \mathrm{L}, 10$ $\mu \mathrm{M})$ were reduced with TCEP $(10 \times$ in excess compared to the disulfide bonds) at room temperature for 20 min. Derivatization of the nascent free - $\mathrm{SHs}$ by $\mathrm{CH}_{3} \mathrm{CH}_{2} \mathrm{HgCl}$ and $\mathrm{CH}_{3} \mathrm{HgCl}(2.5 \times$ in excess compared to TCEP) was performed in the dark for $20 \mathrm{~min}$.

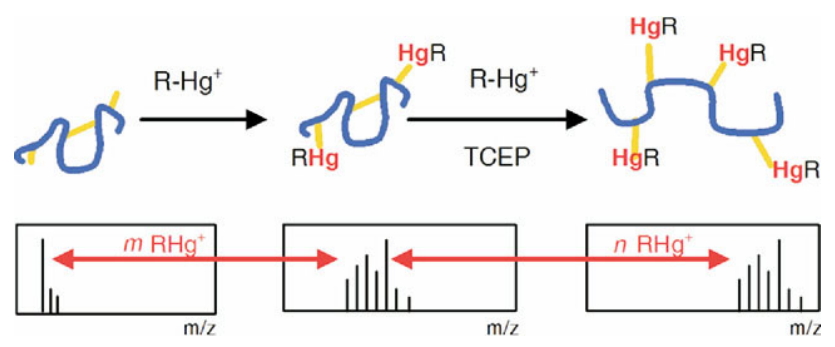

Scheme 1. The $-\mathrm{SHs}$ and $-\mathrm{S}-\mathrm{S}-$ of a peptide or protein labeled with $\mathrm{RHg}^{+}$.
$\beta$-Lactoglobulin $(5 \mu \mathrm{M})$ was directly mixed with a 2.5-fold excess amount of $\mathrm{CH}_{3} \mathrm{HgCl}$ to react with free sulfhydryl. Then the solution was heated in $8 \mathrm{M}$ urea to denature the labeled $\beta$-lactoglobulin and treated in the same way as lysozyme to label disulfide bonds at room temperature for $1 \mathrm{~h}$.

Isolation of the labeled peptide/protein was carried out on an Agilent 1100 series chromatographic system (Agilent Technologies, Palo Alto, CA, USA) using a Zorbax C-18 column (1.0 I.D. $\times 150 \mathrm{~mm}$ long, $3.5 \mu \mathrm{m}$ ). A gradient elution program was used to linearly increase the percentage of mobile phase B $(0.3 \%$ acetic acid in acetonitrile) from 10 to $60 \%$ while decreasing the mobile phase A $(0.3 \%$ acetic acid in UPW) from 90 to $40 \%$ with a flow rate of $0.05 \mathrm{~mL} / \mathrm{min}$. The HPLC was directly coupled to an Esquire-LC ESI ion trap mass spectrometer (Bruker Daltonics, Bremen, Germany). All MS experiments were performed in the positive-ion mode. The operational parameters were as follows: nebulizer, 22 psi; dry gas, $12 \mathrm{~L} / \mathrm{min}$; dry temperature, $300{ }^{\circ} \mathrm{C}$; capillary, $-3500 \mathrm{~V}$; endplate offset, $-500 \mathrm{~V}$; skim 1, 35.0 V; skim 2, 6.0 V; capillary exit offset, $60.0 \mathrm{~V}$; octopole, $2.80 \mathrm{~V}$; lens $1,-5.0 \mathrm{~V}$; lens $2,-60.0 \mathrm{~V}$; trap drive, 55.0; and max accumulation time, $50.00 \mathrm{~ms}$.

\section{Results and Discussion}

\section{Counting Free Sulfhydryls (-SHs)}

GSH, which is a tripeptide (Glu-Cys-Gly), contains one free sulfhydryl. A typical ESI mass spectrum of GSH at $m / z 308$ is shown in Figure 1a. Figure $1 \mathrm{~b}$ shows the mass spectrum of the GSH labeled by one HOOC $-\mathrm{C}_{6} \mathrm{H}_{4}-\mathrm{Hg}^{+}$, indicating that the complex mass shifts to the higher mass region at $m / z 626,627$, $628,629,630,631,632$, and 633 arising from the natural isotopic distribution of $\mathrm{Hg}$. The isotopic distribution observed coincides with that from theoretical calculation. Figure 1c shows that GSH labeled by $\mathrm{CH}_{3} \mathrm{Hg}^{+}$gave a similar result. The visible characteristic isotopic distribution is of particular significance to offer solid evidence for the labeled - $\mathrm{SH}$, making the MS technique a superior alternative for counting - SHs.

When peptides or proteins contain more free $-\mathrm{SH}$ groups, the $\mathrm{RHg}^{+}$also shows great efficiency as an MS-tag. $\mathrm{PC}_{3}$, which has the structure $(\gamma-\mathrm{Glu}-\mathrm{Cys})_{3}-\mathrm{Gly}$, was chosen as a model peptide (Figure 2a). Although HOOC $-\mathrm{C}_{6} \mathrm{H}_{4}-\mathrm{Hg}^{+}$has been used to label $-\mathrm{SHs}$, we always obtain incompletely derivatized $\mathrm{PC}_{3}$ (data not shown) because of the steric hindrance arising from the close arrangement of - $\mathrm{SH}$ in the molecule. Considering that the dissociation constant between $\mathrm{CH}_{3} \mathrm{Hg}^{+}$and cysteine is as low as $10^{-20.3}$ [15], that the ratio of the dissociation constants of $\left[\mathrm{CH}_{3} \mathrm{Hg}-\mathrm{GS}\right]$ to [HOOC $-\mathrm{C}_{6} \mathrm{H}_{4} \mathrm{Hg}-\mathrm{GS}$ ] is $10^{-1.11}$ estimated by ESI-MS (data not shown), as well as the fact that $\mathrm{CH}_{3} \mathrm{Hg}^{+}$has a much smaller size compared with $\mathrm{HOOC}-\mathrm{C}_{6} \mathrm{H}_{4}-\mathrm{Hg}^{+}$, $\mathrm{CH}_{3} \mathrm{Hg}^{+}$should serve as a better MS-tag. This is evidenced by the result that the three $-\mathrm{SHs}$ in $\mathrm{PC}_{3}$ have 


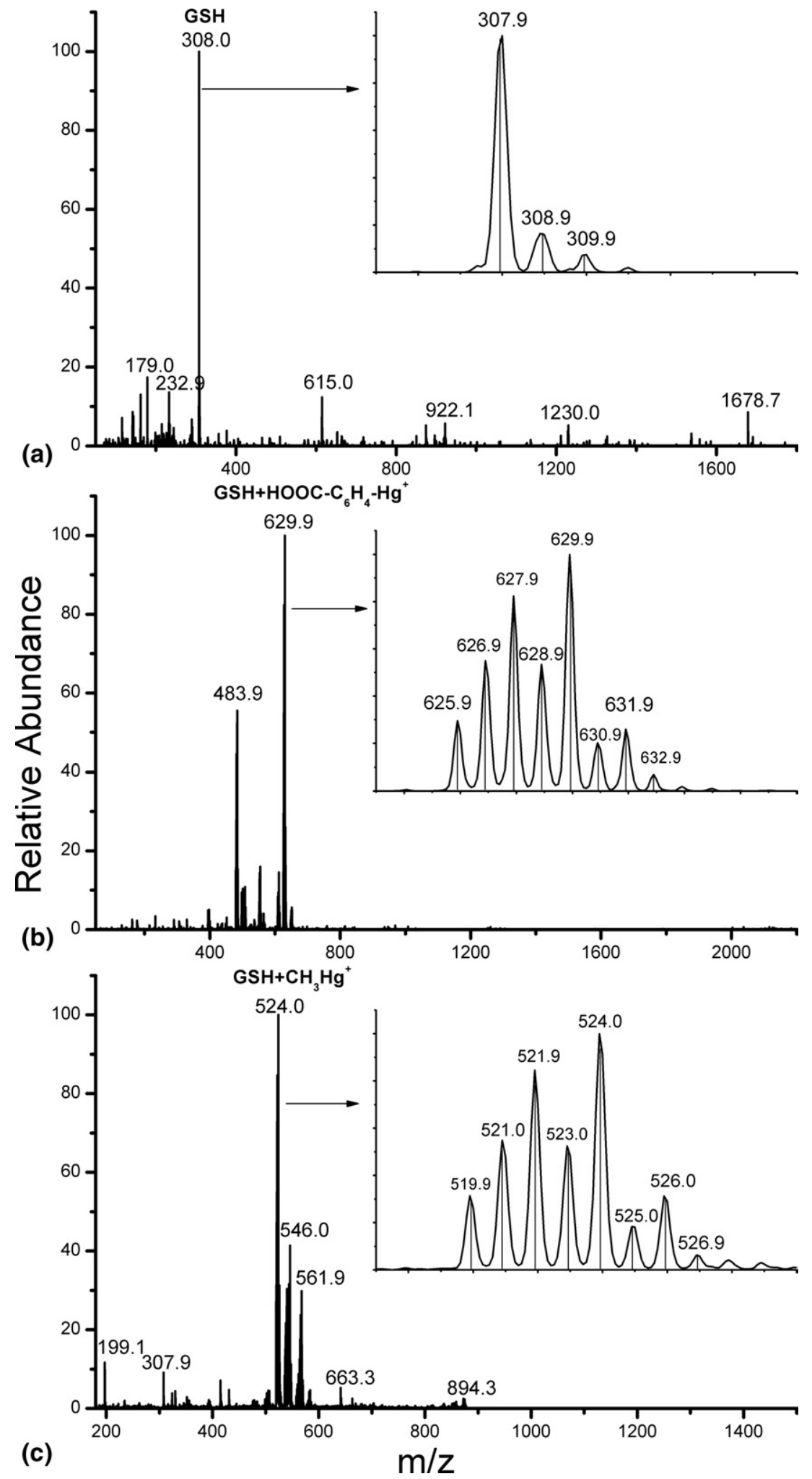

Figure 1. ESI-MS spectra of (a) native form of GSH $(308 \mathrm{~m} / \mathrm{z})$; (b) GSH labeled by HOOC $-\mathrm{C}_{6} \mathrm{H}_{4}-\mathrm{Hg}^{+}$, with peaks at $\mathrm{m} / \mathrm{z} 626,627,628,629,630,631,632$, and 633 arising from the natural isotopic distribution of $\mathrm{Hg}$; (c) GSH labeled by $\mathrm{CH}_{3}-\mathrm{Hg}^{+}$, with peaks at $m / z 520,521,522,523$, $524,525,526$, and 527 arising from the natural isotopic distribution of $\mathrm{Hg}$. 


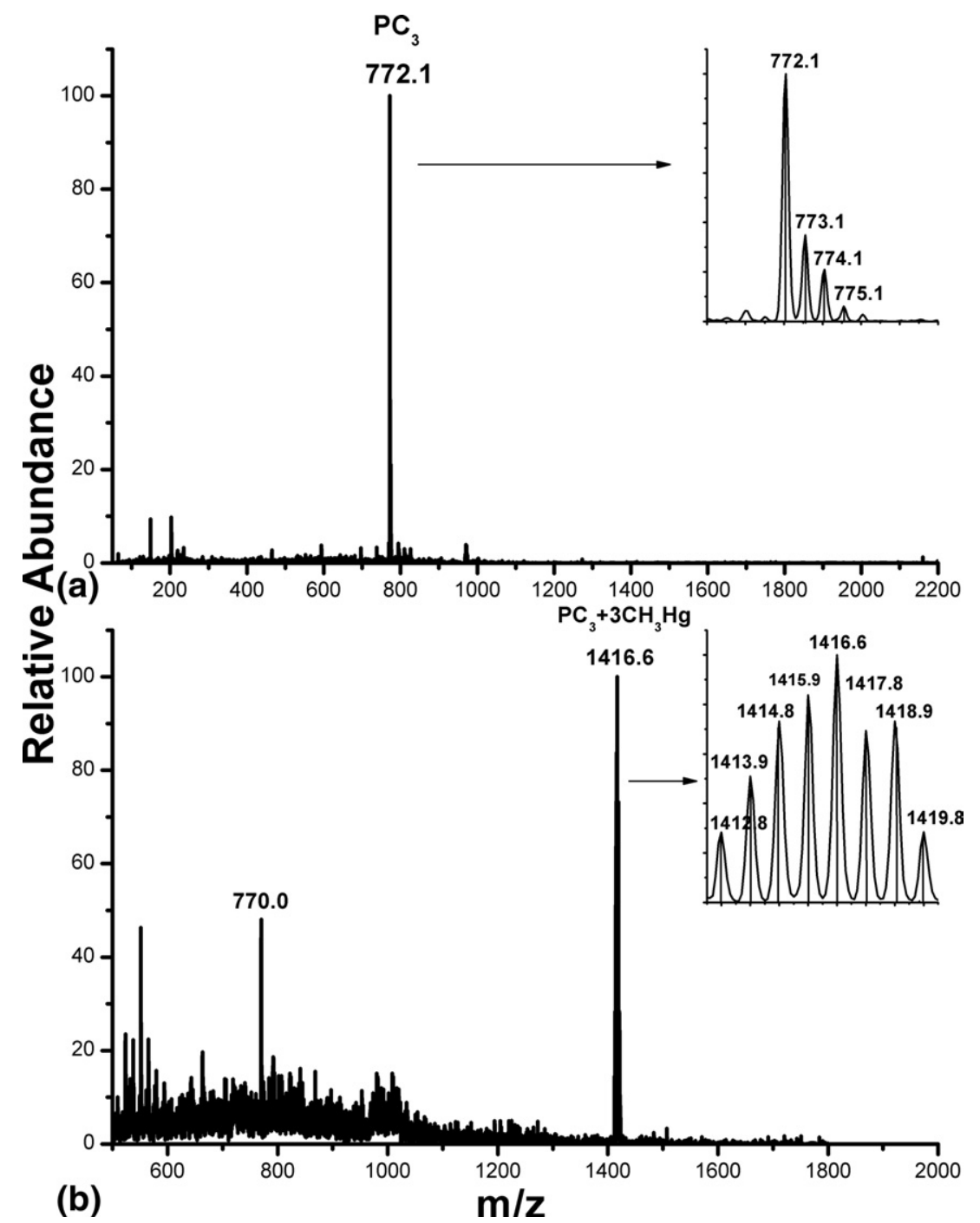

Figure 2. ESI-MS spectra of (a) native form of $\mathrm{PC}_{3}(772 \mathrm{~m} / \mathrm{z})$; (b) $\mathrm{PC}_{3}$ labeled by $\mathrm{CH}_{3} \mathrm{Hg}^{+}$, where three -SHs have completely reacted with $3 \times \mathrm{CH}_{3} \mathrm{Hg}^{+}$, with peaks from $\mathrm{m} / \mathrm{z} 1412.8$ to $\mathrm{m} / \mathrm{z} 1419.8$ arising from the isotopic distribution of $\mathrm{Hg}$. The influence of the $\mathrm{Hg}$ factor weight on the isotopic distribution pattern is decreasing compared with Figure $1 \mathrm{~b}$ and $\mathrm{c}$.

been completely labeled by $3 \times \mathrm{CH}_{3} \mathrm{Hg}^{+}$, as shown in Figure $2 b$.

\section{Counting Disulfide Bonds (-S-S-)}

Lysozyme from hen egg white was chosen as a model protein to demonstrate the feasibility of the proposed strategy for counting the $-\mathrm{S}-\mathrm{S}-$ in a protein. The intact disulfide folding of lysozyme has been well studied [16]. Lysozyme contains eight cysteines, giving rise to four - S-S- (Cys6-Cys127, Cys30-Cys115, Cys64-Cys80, and Cys76-Cys94). As shown in Figure $3 a$, the intact lysozyme shows a series of multicharged ions ranging from +10 to +16 . The deconvoluted MW is $14,303.9$. Figure $3 \mathrm{~b}$ shows the spectrum of completely labeled lysozyme after being reduced by TCEP, where the eight free - $\mathrm{SHs}$ in the reduced lysozyme were all labeled by $\mathrm{C}_{2} \mathrm{H}_{5} \mathrm{Hg}^{+}$. Although some of the $-\mathrm{SHs}$ must be "partially buried" by their surrounding amino acids, there is little impact of steric hindrance for $\mathrm{C}_{2} \mathrm{H}_{5} \mathrm{Hg}^{+}$ and it is accessible to all the - $\mathrm{SHs}$ in the lysozyme because of its smaller size. Similar results obtained using $\mathrm{CH}_{3} \mathrm{Hg}^{+}$as an MS-tag (Supplemental Figure $\mathrm{S1b}$, which can be found in the electronic version of this article) suggest that the size of $\mathrm{C}_{2} \mathrm{H}_{5} \mathrm{Hg}^{+}$and/or $\mathrm{CH}_{3} \mathrm{Hg}^{+}$is small enough to gain access to all $-\mathrm{SHs}$, so there is no need to denature the protein before reduction. The deconvoluted MW of labeled lysozyme is 16,139.9. The shift mass discrepancy is just $8 \times$ $\mathrm{C}_{2} \mathrm{H}_{5} \mathrm{Hg}^{+}$, indicating that four $-\mathrm{S}-\mathrm{S}-$ exist in lysozyme. It should be noted that there are different labeled intermediate products during the labeling process, such as $1 \times \mathrm{C}_{2} \mathrm{H}_{5} \mathrm{Hg}^{+}, 2 \times \mathrm{C}_{2} \mathrm{H}_{5} \mathrm{Hg}^{+}$, and so forth (data not shown), suggesting that the $\mathrm{C}_{2} \mathrm{H}_{5} \mathrm{Hg}^{+}$labeling process is performed stepwise, but the intermediates exist only during the labeling process. Our results show 
that when the organic mercury has a 10 -fold molar excess compared to that of the cysteine groups, given enough reaction time (20 $\mathrm{min}$ to $1 \mathrm{~h}$ ), the final product is completely labeled. Clearly, intensive studies should be carried out to obtain a detailed delineation of the dynamic process involved.

\section{Counting Both Free Sulfhydryls and Disulfide Bonds}

$\beta$-Lactoglobulin contains one free sulfhydryl (Cys121) and two disulfide bonds (Cys66-Cys160 and Cys106Cys119) [17]. It is a good model to demonstrate our strategy. Figure 4a shows the ESI mass spectrum of intact $\beta$-lactoglobulin A (deconvoluted $\mathrm{MW}=18,361.3$ ) and $\beta$-lactoglobulin $\mathrm{B}$ (deconvoluted $\mathrm{MW}=18,275.5$ ). Free $-\mathrm{SH}$ in $\beta$-lactoglobulin is treated directly with $\mathrm{CH}_{3} \mathrm{Hg}^{+}$for derivatization. In Figure $4 \mathrm{~b}$ new pairs of peaks are observed that correspond to derivatized $\beta$-lactoglobulin and yield a mass shift of 215.6 Da. Then the disulfide bonds in $\beta$-lactoglobulin were reduced by TCEP and the resulting nascent - SHs were derivatized immediately by $\mathrm{CH}_{3} \mathrm{Hg}^{+}$. Figure $4 \mathrm{c}$ shows that $\beta$-lactoglobulin is completely labeled by $5 \times$ $\mathrm{CH}_{3} \mathrm{Hg}^{+}$. Figure 4c, like Figure 3b, looks much noisier than the original spectrum of the unmodified protein. The results show that the ionizability of labeled

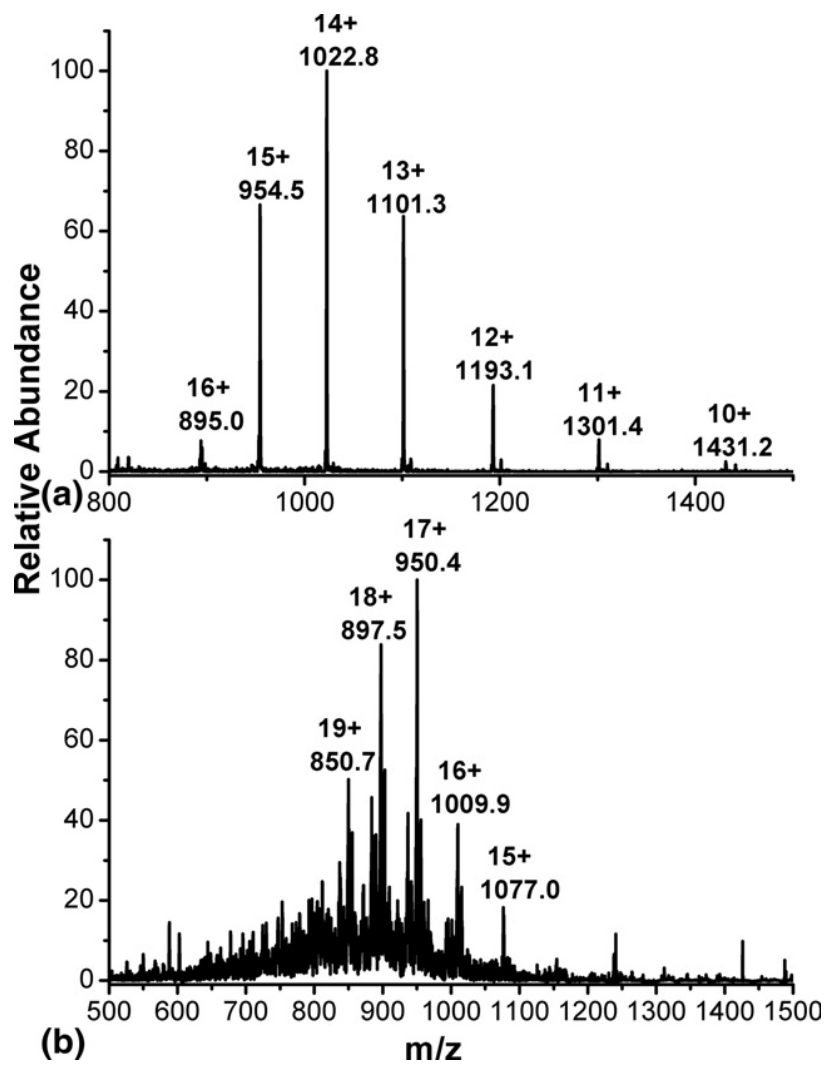

Figure 3. ESI-MS spectra of lysozyme without labeling and with labeling by $\mathrm{C}_{2} \mathrm{H}_{5} \mathrm{Hg}^{+}$: (a) intact lysozyme, with the deconvoluted MW: 14,303.9; (b) the lysozyme completely labeled by $8 \times$ $\mathrm{C}_{2} \mathrm{H}_{5} \mathrm{Hg}^{+}$, with the deconvoluted MW: 16,139.9.

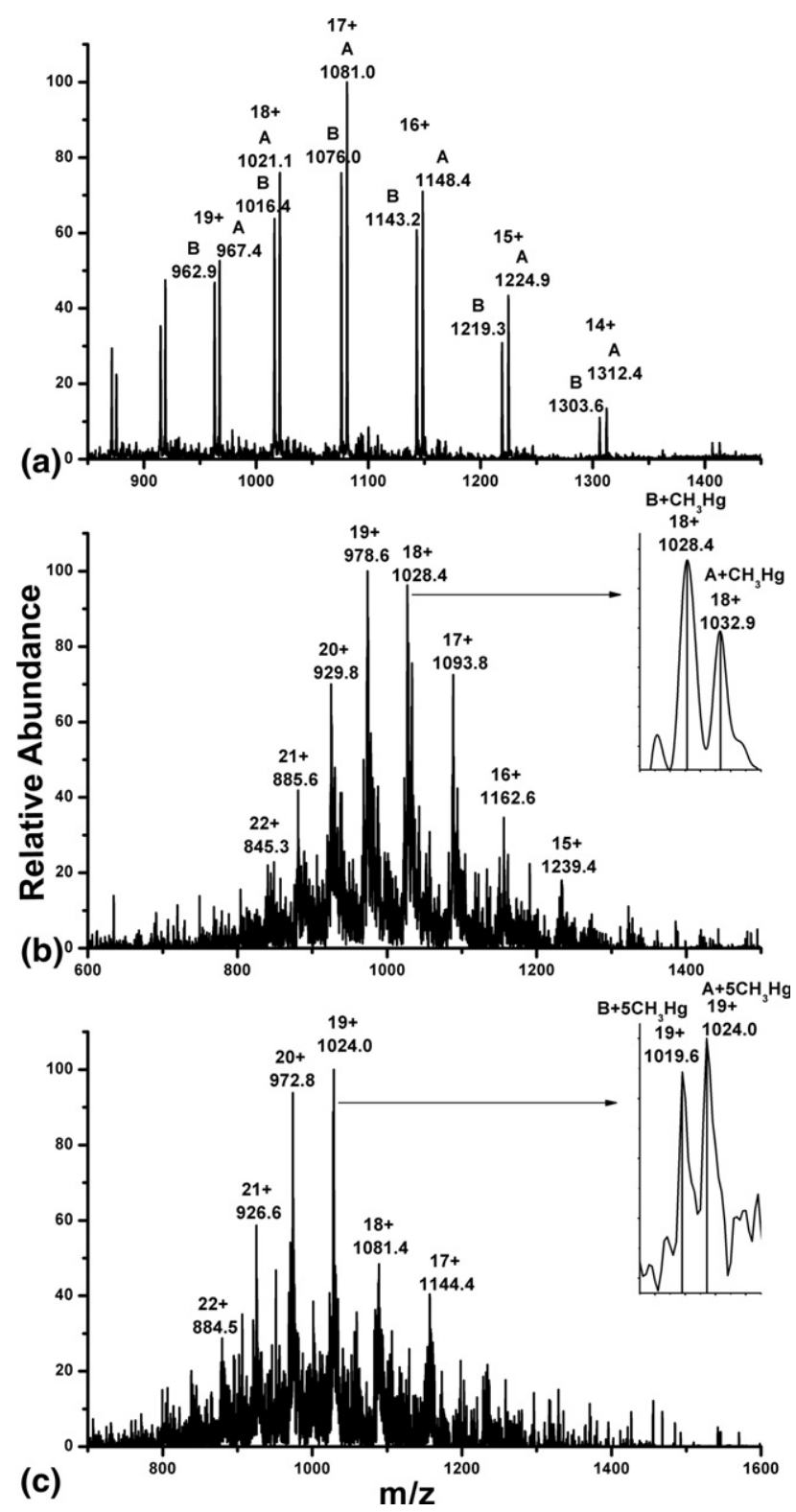

Figure 4. ESI-MS spectra of $\beta$-lactoglobulin without labeling and with labeling by $\mathrm{CH}_{3} \mathrm{Hg}^{+}$: (a) intact $\beta$-lactoglobulin $\mathrm{A}$ and $\mathrm{B}$, their deconvoluted MW are 18,361.3 and 18,275.5, respectively; (b) free sulfhydryl of $\beta$-lactoglobulin labeled by $\mathrm{CH}_{3} \mathrm{Hg}^{+}$, MWs of A and B shift to $18,576.8$ and $18,491.7$; (c) $\beta$-lactoglobulin completely labeled by $5 \times \mathrm{CH}_{3} \mathrm{Hg}^{+}$. The corresponding MWs of A and B are 19438.7 and 19353.3.

peptides/proteins decreases with increasing $\mathrm{RHg}^{+}$ content. However, the spectra still offer enough information for precisely counting the sulfhydryls and disulfide bonds in the proteins, and their ionizability maintains the same order of magnitude as the traditional iodoacetamide derivatization (Figure S1b and c).

\section{Conclusion}

$\mathrm{RHg}^{+}$interacts specifically with the - SHs of peptides and/or proteins at room temperature, such that the resulting stable, soluble, and covalently bonded biocon- 
jugates exhibit great potential for the application of $\mathrm{RHg}^{+}$as a promising alternative MS-tag for screening peptides and proteins by HPLC/ESI-MS. It provides an alternative strategy to count the number of - $\mathrm{SHs}$ and - S - S - involved, offering valuable information for proteomic studies. Such information is not only important to protein chemistry, but also crucial to the quantitative analysis of peptides and/or proteins when a hard ionization source mass spectrometry, such as inductively coupled plasma mass spectrometry (ICPMS) $[18,19]$, is applied to overcome the relatively low ionization ability of ESI-MS for labeled peptides and/or proteins. Both quantification of a protein and locating - SHs and $-S-S-$ in a protein with ESI-MS together with ICP-MS using $\mathrm{RHg}^{+}$as a tag will be the subjects of future studies.

\section{Acknowledgments}

This study was financially supported in part by the National Natural Science Foundation of China $(20535020,20775062)$ and the National 863 Hi-Tech Project (2006AA06Z404). We thank Prof. John Hodgkiss for assistance with English.

\section{References}

1. Choi, H. J.; Kim, S. J.; Mukhopadhyday, P.; Cho, S.; Woo, J. R.; Storz, G.; Ryu, S. E. Structural Basis of the Redox Switch in the OxyR Transcription Factor. Cell 2001, 105, 103-113.

2. Wedemeyer, W. J.; Welker, E.; Narayan, M.; Scheraga, H. A. Disulfide Bonds and Protein Folding. Biochemistry 2000, 39, 4207-4216.

3. Pe'ter, I.; Felder, C. E.; Man, O.; Silman, I.; Sussman, J. L.; Beckmann, J. S. Proteomic Signatures: Amino Acid and Oligopeptide Compositions Differentiate among Phyla. Proteins 2004, 54, 20-40.

4. Tyagarajan, K.; Pretzer, E.; Wiktorowicz, J. E. Thiol-Reactive Dyes for Fluorescence Labeling of Proteomic Samples. Electrophoresis 2003, 24, 2348-2358.

5. Kawakami, S. K.; Gledhill, M.; Achterberg, E. P. Determination of Phytochelatins and Glutathione in Phytoplankton from Natural Water Using HPLC with Fluorescence Detection. Trends Anal. Chem. 2006, 25, 133-142.
6. Nemirovskiy, O. V.; Gross, M. L. Complexes of Iron (II) with CysteineContaining Peptides in the Gas Phase. J. Am. Soc. Mass Spectrom. 1996, 7, 977-980.

7. Nemirovskiy, O. V.; Gross, M. L. Gas Phase Studies of the Interactions of $\mathrm{Fe}^{2+}$ with Cysteine-Containing Peptides. J. Am. Soc. Mass Spectrom. 1998, 9, 1285-1292.

8. Rabenstein, D. L.; Fairhurst, M. T. Nuclear Magnetic Resonance Studies of the Solution Chemistry of Metal Complexes. XI. Binding of Methylmercury by Sulfhydryl-Containing Amino Acids and by Glutathione. J. Am. Chem. Soc. 1975, 97, 2086-2092.

9. Li, Y.; Yan, X. P.; Chen, C.; Xia, Y. L.; Jiang, Y. Human Serum Albumin-Mercurial Species Interactions. J. Proteome Res. 2007, 6, 2277 2286.

10. Rubino, F. M.; Verduci, C.; Giampiccolo, R.; Pulvirenti, S.; Brambilla, G. Colombi, A. Molecular Characterization of Homo- and Heterodimeric Mercury(II)-bis-thiolates of Some Biologically Relevant Thiols by Electrospray Ionization and Triple Quadrupole Tandem Mass Spectrometry. J. Am. Soc. Mass Spectrom. 2004, 15, 288-300.

11. Takatera, K.; Watanabe, T. Determination of Sulfhydryl Groups in Ovalbumin by High-Performance Liquid Chromatography with Inductively Coupled Plasma Mass Spectrometric Detection. Anal. Chem. 1993, 65, 3644-3646.

12. Zaluzec, E. J.; Gage, D. A.; Watson, J. T. Quantitative Assessment of Cysteine and Cystine in Peptides and Proteins Following Organomercurial Derivatization and Analysis by Matrix-Assisted Laser Desorption Ionization Mass Spectrometry. J. Am. Soc. Mass Spectrom. 1994, 5, 359-366.

13. Bramanti, E.; Lomonte, C.; Galli, A.; Onor, M.; Zamboni, R.; Raspi, G.; D'Ulivo, A. Characterization of Denatured Metallothioneins by Reversed Phase Coupled with On-line Chemical Vapour Generation and Atomic Fluorescence Spectrometric Detection. J. Chromatogr. A 2004 1054, 285-291.

14. Chen, L. Q.; Guo, Y. F.; Yang, L. M.; Wang, Q. Q. SEC-ICP-MS and ESI-MS/MS for Analyzing In Vitro and In Vivo Cd-Phytochelatin Complexes in a Cd-Hyperaccumulator Brassica chinensis. J. Anal. At. Spectrom. 2007, 22, 1403-1408.

15. Simpson, R. B. Association Constants of Methylmercury with Sulfhydryl and Other Bases. J. Am. Chem. Soc. 1961, 83, 4711-4717.

16. Blake, C. C.; Koening, D. F.; Mair, G. A.; North, A. C.; Phillips, D. C. Sarma, V. R. Structure of Hen Egg-white Lysozyme. A Threedimensional Fourier Synthesis at 2 Angstrom Resolution. Nature 1965, 206, 757-761.

17. Kuwata, K.; Hoshino, M.; Forge, V.; Era, S.; Batt, C. A.; Goto, Y. Solution Structure and Dynamics of Bovine Beta-Lactoglobulin A. Protein Sci. 1999, 8, 2451-2542.

18. Zhang, C.; Wu, F. B.; Zhang, X. R. ICP-MS-based Competitive Immunoassay for the Determination of Total Thyroxin in Human Serum. J. Anal. At. Spectrom. 2002, 17, 1304-1307.

19. Hu, S. H.; Zhang, S. C.; Hu, Z. C.; Xing, Z.; Zhang, X. R. Detection of Multiple Proteins on One Spot by Laser Ablation Inductively Coupled Plasma Mass Spectrometry and Application to Immuno-Microarray with Element-Tagged Antibodies. Anal. Chem. 2007, 79, 923-929. 